\section{RESULTS OF AN AUTOLOGOUS TISSUE RECONSTRUCTION FOR REPLACEMENT OF OBSTRUCTED EXTRACARDIAC CONDUITS}

Between May 1983 and March 1, 1995, 50 patients had replacement of an obstructed pulmonary ventricle-pulmonary artery conduit with an autologous tissue reconstruction in which a prosthetic roof was placed over the fibrous tissue bed of the explanted conduit. The roof was constructed with xenograft pericardium (most recently) $(n=42)$, homograft dura mater $(n=5)$, or Dacron fabric $(n=3)$. Patient ages ranged from 5 to 34 years (median 16 years). The explanted conduits were Hancock conduits $(n=33$ ), Tascon conduits $(n=6)$, homograft $(n=4)$, Dacron tube $(n=3)$, and others $(n=4)$. Preoperative maximum systolic gradients ranged from 44 to $144 \mathrm{~mm} \mathrm{Hg}$ (median $78 \mathrm{~mm} \mathrm{Hg}$ ). Thirty-seven concomitant cardiac procedures were done in 29 patients. When a valve was necessary ( $n=15$ ), it was possible to place a large-sized valve in the autologous tissue reconstructions (range 22 to $29 \mathrm{~mm}$, median $26 \mathrm{~mm}$ ). Cardiopulmonary bypass times ranged from 34 to 223 minutes (median 84 minutes), and aortic crossclamp times ranged from 0 (in 32 patients) to 109 minutes (median 0 minutes). Intraoperative postrepair peak systolic gradients from pulmonary ventricle to pulmonary artery ranged from 0 to $33 \mathrm{~mm} \mathbf{H g}$ (median $13 \mathrm{~mm} \mathrm{Hg}$ ). There was one early death $(2 \%)$ in a patient who had additional cardiac procedures. Follow-up was complete in all patients and ranged from 1 month to 11.8 years (median 7.5 years). There were two sudden late deaths: conduits in both were known to be free from obstruction. Forty-four of the 47 surviving patients had evaluation of the gradient by echocardiography or cardiac catheterization 1 month to 11 years (median 7 years) after operation. The gradients ranged from 5 to $45 \mathrm{~mm} \mathrm{Hg}$ (median $20 \mathrm{~mm} \mathrm{Hg}$ ). None of the conduits developed an obstructive peel, valve obstruction, or valve incompetence. At 10 years, the freedom from reoperation for conduit obstruction was $100 \%$, and freedom from reoperation for any cause was $81 \%$. This technique simplifies conduit replacement, allows for a generous-sized outflow tract, has a low risk, and yields late results that appear superior to those of cryopreserved homografts or other types of extracardiac conduits. (J THORAC CARDIOvasC SuRg 1995;110:1359-68)

Robert J. Cerfolio, MD ${ }^{\text {a }}$ (by invitation), Gordon K. Danielson, MD, ${ }^{a}$ Carole A. Warnes, MD $^{\mathrm{b}}$ (by invitation), Francisco J. Puga, MD, ${ }^{\mathrm{a}}$

Hartzell V. Schaff, MD, ${ }^{a}$ Betty J. Anderson, $\mathrm{RN}^{\mathrm{a}}$ (by invitation), and Duane M. Ilstrup, $\mathrm{MS}^{\mathrm{c}}$ (by invitation), Rochester, Minn.
$\mathrm{T}$ he ideal extracardiac conduit should be easily implanted, lack degeneration or the development of obstruction, allow for growth, be free from insuf-

From the Division of Thoracic and Cardiovascular Surgery, ${ }^{\text {a the }}$ Division of Cardiovascular Diseases, ${ }^{\mathrm{b}}$ and the Department of Medical Statistics and Epidemiology, ${ }^{\mathrm{c}}$ Mayo Clinic/Foundation, Rochester, Minn.

Read at the Seventy-fifth Annual Meeting of The American Association for Thoracic Surgery, Boston, Mass., April 23-26, 1995.

Address for reprints: Gordon K. Danielson, MD, Mayo Clinic, 200 First St. SW, Rochester, MN 55905. ficiency, and not necessitate the use of anticoagulants. As is the case with cardiac valves, the ideal conduit has not yet been developed. Children who undergo pulmonary ventricle-pulmonary artery (PV-PA) connections with prosthetic materials may require multiple reoperations because of conduit failure. (We use the term pulmonary ventricle rather than right ventricle because one patient had corrected transposition in which the pulmonary ventri-

Copyright (C 1995 by Mosby-Year Book, Inc.

$0022-5223 / 95 \$ 5.00+0 \quad \mathbf{1 2 / 6 / 6 7 9 9 6}$ 


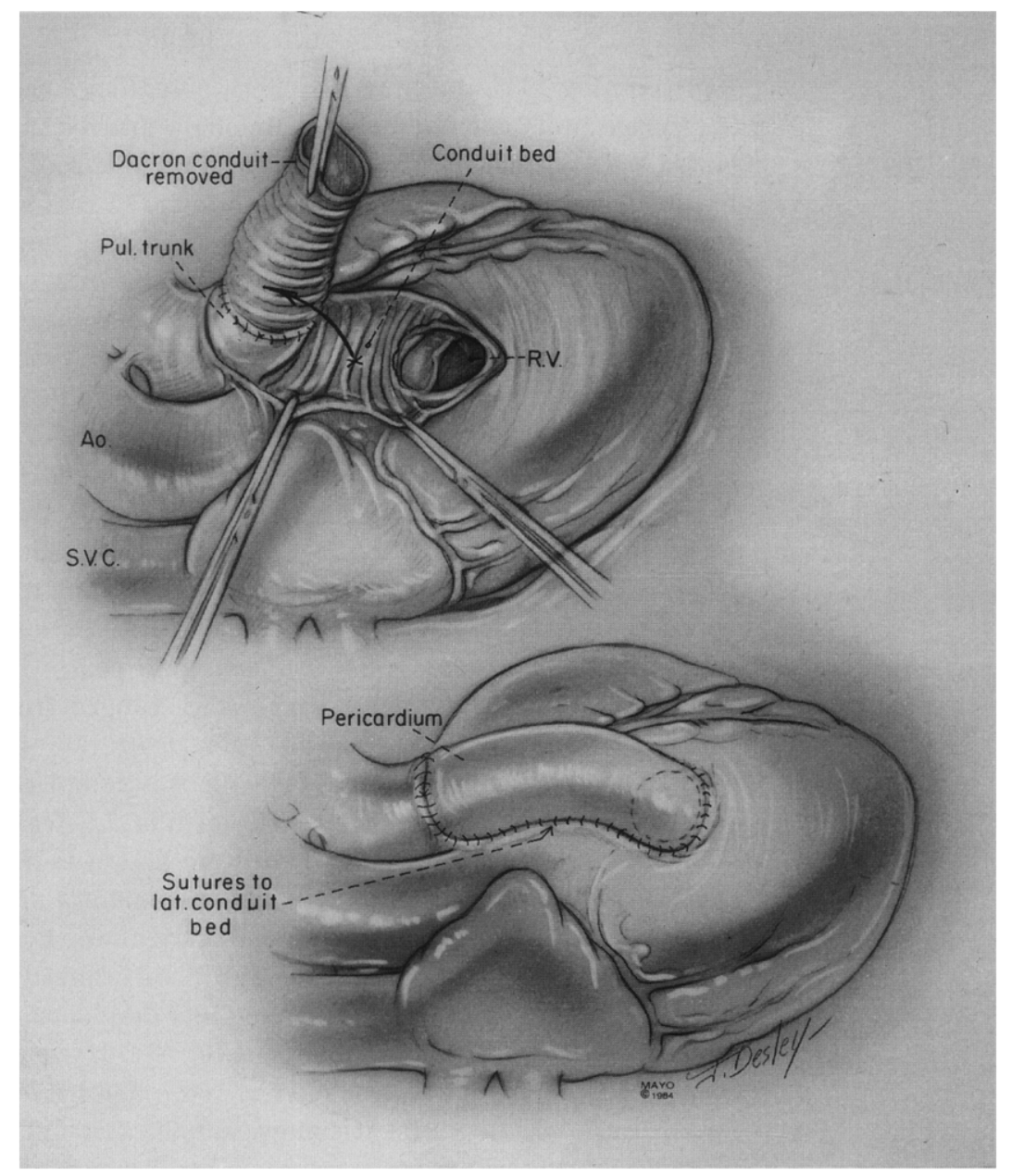

Fig. 1. Technique of autologous tissue reconstruction for replacement of obstructed cardiac conduit. Upper panel shows obstructed Dacron conduit being removed from thick fibrous peel that surrounds it (solid arrow). Lower panel illustrates pericardial roof being sewn to lateral (lat.) edges of fibrous tissue bed. Pul., Pulmonary; $A o$, aorta; $S V C$, superior vena cava; $R V$, right ventricle. (From Danielson GK, Downing TP, Schaff HV, Puga FJ, DiDonato RM, Ritter DG. (J Thorac Cardiovasc Surg 1987;93:555-9.)

cle was the morphologically left ventricle.) We have previously reported a new procedure that replaces an obstructed extracardiac conduit with an autologous tissue reconstruction in which a pericardial roof is placed over the fibrous tissue bed of the explanted conduit (Fig. 1). ${ }^{1}$ The follow-up of these 16 patients and our experience with 34 other patients undergoing a similar procedure are presented.

\section{Patients and methods}

Between May 1983 and March 1, 1995, 50 patients with obstructed PV-PA conduits underwent an autologous tissue reconstruction in which a prosthetic roof was placed over the fibrous tissue bed of the explanted conduit. There were 31 male and 19 female patients with an age range of 5 to 34 years (median 16 years). The conduits in place before the autologous tissue reconstructions were standard Hancock 100 orifices* $(n=19)$, Hancock modified 150 orifices $(n=14)$, Tascon conduits* $(n=6)$, homografts $(n=4)$, Dacron tubes $(n=3)$, Ionescu-Shiley conduitst $(n=2)$, and Carpentier-Edwards conduits $(n=2)$. The sizes of the conduits in place before the reconstructions ranged from 8 to $26 \mathrm{~mm}$ (median $22 \mathrm{~mm}$ ); 46 were valved and 4 were nonvalved (Dacron tube, $n=$ 3 ; Tascon tube, $n=1$ ). More than one previous conduit had been placed in 10 patients: 9 patients had received two and 1 patient had received four previous conduits. Cardiac diagnoses were transposition of the great arteries

* Medtronic Heart Valves, Irvine, Calif.

$\uparrow$ Shiley, Inc., Irvine, Calif.

$\$$ Baxter Healtheare Corp., Edwards Division, Santa Ana, Calif. 
$(n=18)$, pulmonary atresia $(n=14)$, truncus arteriosus $(n=8)$, double-outlet right ventricle $(n=5)$, tetralogy of Fallot $(n=4)$, and corrected transposition $(n=1)$. In 41 patients $(82 \%)$ the conduit coursed to the left of the aorta and in 9 patients it coursed to the right of the aorta. The time between the prior conduit operation and the autologous tissue reconstruction ranged from 1.2 to 20 years (median 8 years), and the primary indication for operation was severe conduit obstruction in all patients. Preoperative systolic gradients measured by cardiac catheterization (peak-to-peak gradients) or echocardiography (maximum instantaneous gradients) ranged from 44 to $144 \mathrm{~mm} \mathrm{Hg}$ (median $78 \mathrm{~mm} \mathrm{Hg}$ ).

The obstructed conduit was exposed via a repeat median sternotomy, which was done with special care because the conduit and valve ring or calcified homograft was often adherent to the sternum or had eroded into it. An attempt was made to perform resternotomy and central cannulation whenever possible, but femoral artery and vein cannulations were required in some patients to establish cardiopulmonary bypass before or during resternotomy. After resternotomy, the heart was exposed sufficiently to allow central cannulation, and the conduit was initially identified but not dissected free. Cardiac chamber, conduit, and distal pulmonary artery pressures were measured when feasible. Single right atrial or double caval cannulation was done, depending on the operative complexity and the necessity of performing associated intracardiac procedures.

In some patients who did not require associated intracardiac procedures and in whom there were no residual intracardiac shunts, the perfusate temperature was lowered to $32^{\circ} \mathrm{C}$ to $34^{\circ} \mathrm{C}$, an aortic tack vent was placed, the heart was kept beating, and the conduit was replaced without crossclamping the aorta. In the other patients, moderate hypothermia $\left(20^{\circ}\right.$ to $\left.28^{\circ} \mathrm{C}\right)$, aortic crossclamping, and myocardial protection with cold blood potassium cardioplegic solution were used. Exposure for the distal anastomosis was often facilitated with short periods of low flow $(0.5 \mathrm{~L} / \mathrm{min}$ per square meter).

A longitudinal incision was made anteriorly over the course of the obstructed conduit, and the conduit was dissected free from the external fibrous peel and excised. The sides and floor of the conduit bed were preserved. Distal suture-line stenoses were relieved and the right and left pulmonary arteries were measured with probes. If they were of normal size or greater and if the preoperative or prebypass distal pulmonary arterial pressure was normal, no valve was used in the reconstruction in many of the patients, especially early in our experience. If the pulmonary arteries were relatively hypoplastic or if pulmonary hypertension was present, a tissue or mechanical valve was always used. The right ventricular outflow tract was examined and any muscular outlet obstruction was resected. Any necessary intracardiac procedures were then done.

When it became available, glutaraldehyde-preserved bovine pericardium was favored for construction of the roof of the new conduit. The suture line was begun distally and the shape of the patch was altered as necessary to provide relief of proximal right or left pulmonary artery stenoses. In some patients, a T-shaped reconstruction of the right and left pulmonary arteries was made with the pericardial patch before it was brought proximally and sewn to the edges of the conduit bed. The suture line was restricted to the fibrous tissue at the edge of the conduit bed to avoid injury to any adjacent, obscured coronary arteries. Before completion of the proximal anastomosis, the newly created PV-PA conduit was sized with dilators. When a valve was required, it was placed so as to minimize compression by the sternum, usually by positioning it as close to the distal anastomosis as possible. However, for patients with pulmonary atresia, it was often possible to place the valve at or just proximal to the level of the pulmonary anulus. The valve was secured with mattress sutures passed through felt pledgets posteriorly and laterally in the conduit bed. Anteriorly, the sewing ring was attached to the pericardial roof patch with a running monofilament suture; this was facilitated by temporarily reflecting the proximal portion of the pericardial patch distally and suturing the resultant pericardial fold to the sewing ring. The proximal pericardial patch was then reflected proximally and sewn to the right ventricular outflow tract to complete the reconstruction.

For those cases in which the heart was kept perfused and beating, removal of the distal conduit and preparations for the distal anastomosis were facilitated by clamping the conduit as far proximally as possible and then dividing the conduit distal to the clamp. After the distal reconstruction was completed and the patch was sutured anteriorly to the level of the clamp, the clamp was removed, the proximal conduit remnant was excised, and the proximal pericardial patch was closed to the pulmonary ventricular outflow tract.

When the patient was weaned from cardiopulmonary bypass, pressures were measured in the pulmonary ventricle and distal pulmonary artery. The lobe of the thymus on the side of the conduit was removed, together with fibrous tissue in the mediastinum and on the chest wall in the region of the reconstruction, to allow maximal room for the conduit. Resection of overlying sternal bone and costal cartilage was done as necessary to prevent compression of the reconstruction.

The quality of the fibrous tissue bed of the explanted conduit varied widely according to the type of conduit. The conduit could be removed most easily when it was made of tightly woven Dacron fabric (for example, the Hancock conduit), and the remaining fibrous tissue bed was of good quality. The Tascon conduit was more firmly embedded in the surrounding fibrous tissue, necessitating a careful dissection to free it from the fibrous bed. Calcified homografts were often managed by removing the calcium with an endarterectomy technique, leaving the adventitia of the homograft and adjacent fibrous tissue as the floor of the new reconstruction. In one of our patients, a satisfactory fibrous floor was not present after excision of the conduit. In this case, a generous-sized pericardial tube was formed with an anterior suture line. A $25 \mathrm{~mm}$ porcine valve was also placed in this conduit.

It is important to know the location of any coronary arteries that course posterior to the conduit to avoid injury to them during removal of the obstructed conduit and when a valve is placed in the new reconstruction. The left coronary artery is most often at risk. The artery can 
Table I. Concomitant cardiovascular procedures

\begin{tabular}{lc}
\hline \multicolumn{1}{c}{ Procedure } & No. of patients \\
\hline Closure of residual ventricular septal defect & 10 \\
Pulmonary angioplasty & 9 \\
Tricuspid annuloplasty & 6 \\
Closure of residual atrial septal defect & 4 \\
Aortic valve. replacement & 4 \\
Aortic patch enlargement & 2 \\
Closure of left ventricle-pulmonary artery fistula & 1 \\
Tricuspid valve replacement & 1
\end{tabular}

either be compressed by an inappropriately placed valve or it can be distorted or obstructed by sutures used to attach the new conduit valve.

Follow-up was achieved by obtaining the records of the most recent examination at our institution, letters from home physicians, and copies of the most recent outside echocardiograms and cardiac catheterization reports. $\mathrm{Pa}-$ tients were asked by telephone interview or questionnaire to grade their health status as excellent, good, fair, or poor. The patient's exercise tolerance was assessed by asking them if they were able to do as much as their peers, half as much, one quarter as much, or less than one quarter as much. Employment and educational statuses were determined. The reproductive status of the female patients was assessed.

Early mortality was defined as any death that occurred before hospital discharge or within 30 days of operation. Survival was estimated by the Kaplan-Meier method with the date of the autologous tissue reconstruction used as the starting point. The influence of variables on survival was analyzed by the log-rank test for discrete variables and the proportional hazards Cox model for continuous variables. Values of $p<0.05$ were considered statistically significant.

\section{Results}

Early results. Thirty patients underwent their second median sternotomy, 17 their third, 2 their fourth, and 1 their fifth. Cannulation was done via the aorta and right atrium in 31 patients, via the femoral artery and right atrium in 8 patients, and via both the femoral artery and vein in 11 patients. The right ventricle was entered during resternotomy in 1 patient. It was recognized before operation that the conduit in this patient had eroded into the posterior table of the sternum, so the femoral vessels were dissected free before the resternotomy was begun. Cardiopulmonary bypass was instituted via the femoral vessels, resternotomy was completed, the right ventricle was repaired, and the conduit reconstruction proceeded uneventfully. The patient did not require any blood transfusions and had an uncomplicated 7-day hospital course.

The 50 roof patches were constructed with glutaraldehyde-preserved bovine pericardium $(n=42)$, homograft dura mater $(n=5)$, or Dacron fabric $(n=3)$. Fifteen patients had valves placed in the conduit; 13 were porcine valves (Carpentier-Edwards valve $[n=12]$ and Tascon valve left in place $[n=1])$ and 2 were mechanical valves (StarrEdwards* $[n=1]$ and Björk-Shiley $\dagger[n=1])$. Thirty of the 42 pericardial roofed conduits, 3 of the 5 dura mater roofed conduits, and 2 of the 3 Dacron fabric roofed conduits were nonvalved.

Thirty-seven concomitant cardiovascular procedures were done in 29 patients as shown in Table I. Cardiopulmonary bypass times ranged from 34 to 223 minutes (median 84 minutes). In 32 patients the aorta was not crossclamped. In the remaining 18 patients the aortic crossclamp time ranged from 10 to 109 minutes (median 68 minutes). Intraoperative postrepair peak systolic conduit gradients measured before closure in 25 patients ranged from 4 to 33 $\mathrm{mm} \mathrm{Hg}$ (median $13 \mathrm{~mm} \mathrm{Hg}$ ). Partial sternal resection with or without concomitant costal cartilage resection was done in 5 patients to prevent conduit compression.

There was one early death $(2 \%)$ in a patient with transposition of the great arteries who underwent reoperation for conduit obstruction, residual ventricular septal defect, and right pulmonary artery stenosis. The prior conduit had eroded into an unrecognized single coronary artery just distal to its origin from the aorta. This artery was exposed during removal of the conduit and was repaired along with the residual ventricular septal defect and the right pulmonary artery stenosis. However, the patient could not be weaned from cardiopulmonary bypass. Nonfatal complications included exploration for control of chest wall bleeding $(n=3)$ and atrial arrhythmias $(n=3)$. Hospital stay in the early survivors ranged from 6 to 23 days (median 9 days).

Late results. Follow-up was complete in all patients and ranged from 1 month to 11.8 years (median 7.5 years). There were two sudden late deaths, both in patients who were in New York Heart Association functional class I. One patient died 4 years after operation while playing a video game, and the other died 5 years after operation after colliding with another player during a baseball game. Both had had recent echocardiograms that showed no evidence of conduit obstruction. In 44 of the surviving 47 patients, the PV-PA conduits were

*Baxter Healthcare Corp., Santa Ana, Calif. †Shiley, Inc., Irvine, Calif. 


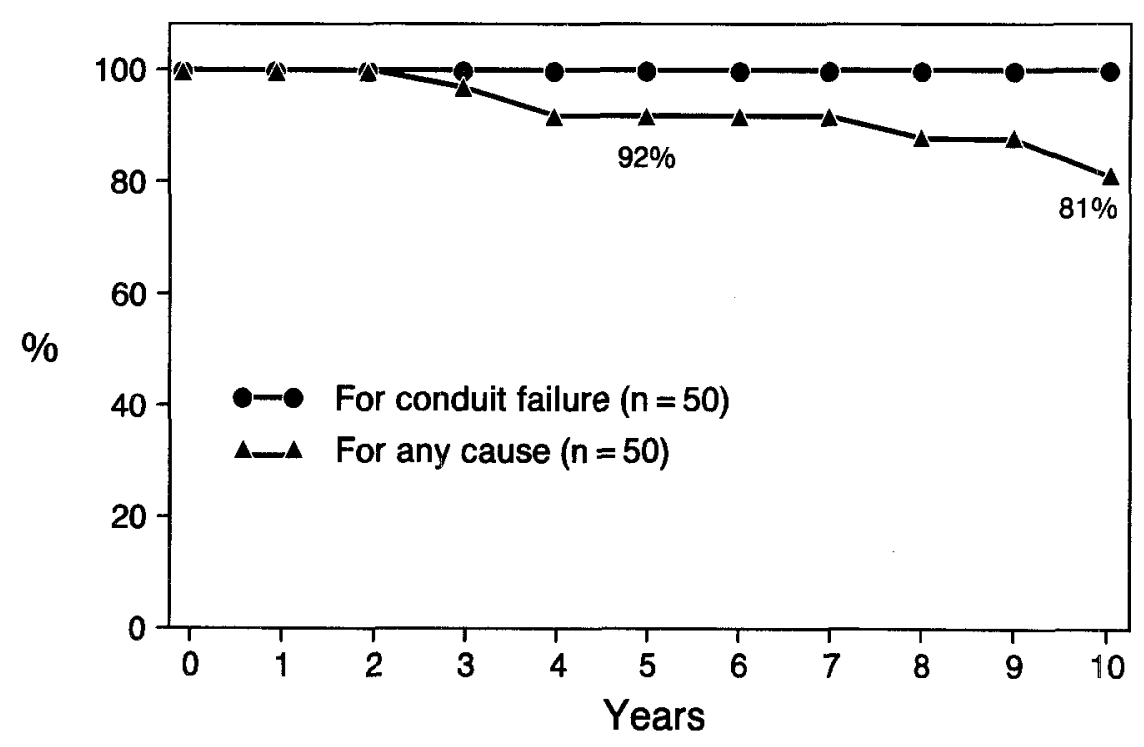

Fig. 2. Freedom from reoperation because of conduit failure and any cause.

evaluated by echocardiography $(n=43)$ or cardiac catheterization $(n=1) 1$ month to 11 years (median 7 years) after operation. The median follow-up for the 15 patients with valved conduits was 6 years and for the 35 patients with nonvalved conduits was 7 years. Conduit gradients varied from 5 to $45 \mathrm{~mm} \mathrm{Hg}$ (median $20 \mathrm{~mm} \mathrm{Hg}$ ).

Five patients required reoperation; all had received nonvalved reconstructions. The median age at operation for the patients receiving valved conduits was 19 years (range 11 to 34 years) and the median age at operation for the patients receiving nonvalved conduits was 15 years (range 5 to 27 years) $(p=$ not significant). Three patients, aged 19 , 20 , and 30 years at the time of receiving a nonvalved reconstruction, subsequently underwent placement of a valve in the pulmonary position because of symptoms of the right side of the heart, right ventricular dilatation, and a concern about deteriorating right ventricular function. These patients had undergone two, two, and three cardiac operations before the nonvalved reconstructions, respectively. One of the three, in whom pulmonary hypertension, right pulmonary artery stenosis, and tricuspid insufficiency had developed, underwent insertion of a cryopreserved aortic homograft, enlargement of the right pulmonary artery, and a tricuspid annuloplasty. Five years later the homograft, which had become calcified and obstructed, was resected and a valved autologous tissue reconstruction was done. A sec- ond patient, in whom atrial and ventricular arrhythmias had developed, underwent insertion of a cryopreserved pulmonary homograft and a pacemaker cardioverter-defibrillator. The third patient received a cryopreserved pulmonary homograft; two years later, reoperation was necessitated by homograft obstruction, and a new pulmonary homograft was placed.

Conduit failure was defined as need for reoperation because of conduit stenosis or extrinsic compression, conduit valve insufficiency, or anastomotic dehiscence or aneurysm. Freedom from reoperation for conduit failure was $100 \%$ (Fig. 2). Freedom from reoperation for any cause was $92 \%$ at 5 years and $81 \%$ at 10 years (Fig. 2). Freedom from reoperation for any cause for the 35 patients with nonvalved conduits was $90 \%$ at 5 years and $77 \%$ at 10 years (Fig. 3). Freedom from reoperation for any cause for the 15 patients with valved conduits was $100 \%$ at both 5 and 10 years $(p=0.30)$.

Of the 47 late survivors, $40(85 \%)$ rated their health status as excellent and $7(15 \%)$ rated it as good. Four patients had one or more episodes of tachyarrhythmia and one reported dull chest pain; the remaining 42 patients were free of symptoms. Forty-three patients said that they could do as much as their peers and 4 patients said they could do about half as much. Fourteen of the 15 patients (93\%) currently in school are able to take courses full time and 17 of the 19 patients (89\%) employed 


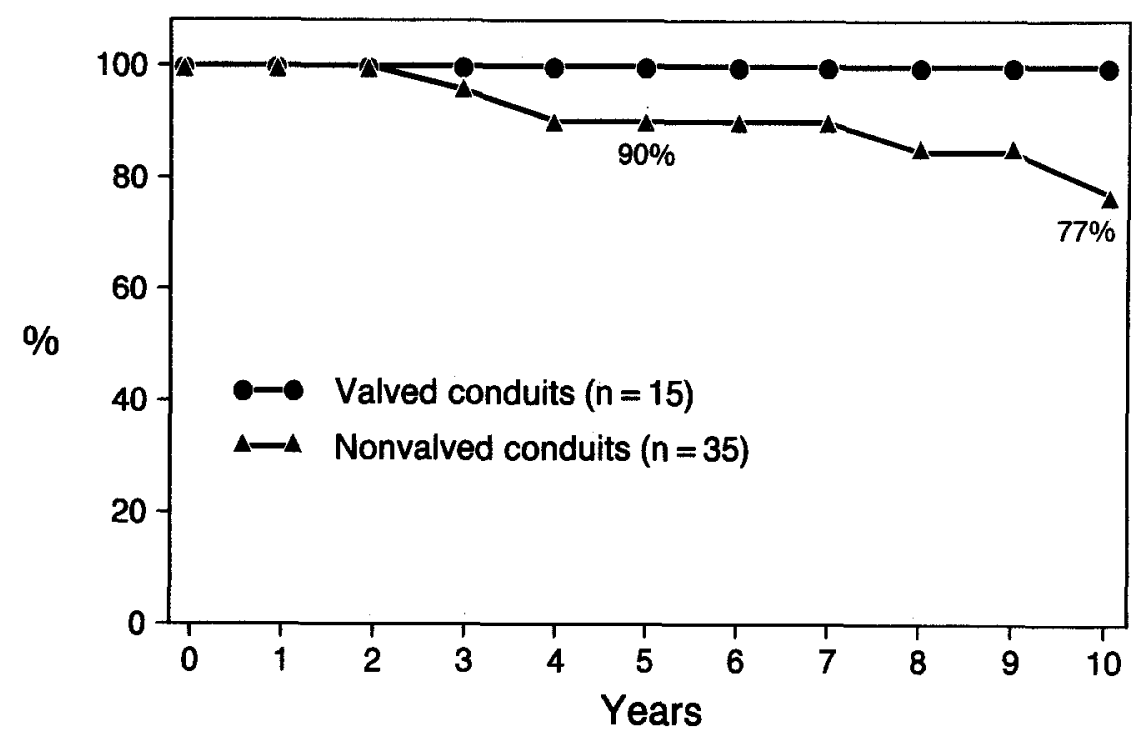

Fig. 3. Freedom from reoperation because of any cause for valved and nonvalved conduits.

outside the home work 40 hours or more per week. One patient has had an uneventful pregnancy and delivery of a normal, healthy child.

\section{Discussion}

The development of the extracardiac conduit has been one of the greatest advances in cardiac surgery. Conduits have decreased the mortality of several standard operations and have made possible correction of numerous complex congenital cardiac anomalies that previously were uncorrectable. However, as is the case with cardiac valves, the ideal conduit has not yet been developed. Our first extended experience with conduits used the irradiated aortic homograft. ${ }^{2,3}$ The wall of this homograft calcified, often within 1 year, and the valve subsequently calcified and degenerated, resulting in both conduit stenosis and insufficiency. The next conduit we used (in 1972) was the Hancock conduit, a commercially available Dacron tube containing a glutaraldehydepreserved porcine valve. This conduit had the advantage of ready availability in many sizes, and it was longer and more versatile in the repair of various pulmonary artery anomalies. The Hancock conduits lasted longer than the irradiated homografts (Fig. 4), but the porcine valve also calcified with time and became both stenotic and insufficient. In addition, these conduits developed obstructive peels, ${ }^{4,5}$ a complication not seen in the homografts. Another unanticipated complication was dissection behind the peel caused by incomplete neointimal healing in the conduit. ${ }^{4,5}$ Major stenoses in the Hancock conduits occurred at the valve alone in approximately one third, because of intimal peel in the graft in one third, and in both the valve and the graft in one third. ${ }^{4}$ In our experience, more recently available Dacron conduits with porcine or pericardial valves (Tascon, Carpentier-Edwards, Ionescu-Shiley conduits) have not shown any long-term advantages compared with the Hancock conduit.

Attempts at our institution to reduce the prevalence of late conduit failure have included the use of nonvalved tube grafts when the pulmonary artery pressure is expected to be low. ${ }^{6}$ This concept is based on the observation that the vast majority of patients having repair of tetralogy of Fallot with residual pulmonary insufficiency have done well without the need for pulmonary valve placement in a follow-up of 29 to 34 years. $^{7}$ This observation combined with the knowledge that porcine valves contributed to major stenoses in two thirds of obstructed Hancock conduits influenced us to use a nonvalved autologous tissue reconstruction in suitable patients. The pulmonary insufficiency was tolerated well in most of the patients, but was associated with late development of right ventricular enlargement and reduced right ventricular ejection fraction in three patients, one of whom also had tricuspid insufficiency. When this occurred, reoperation was offered for placement of a pulmonary valve 


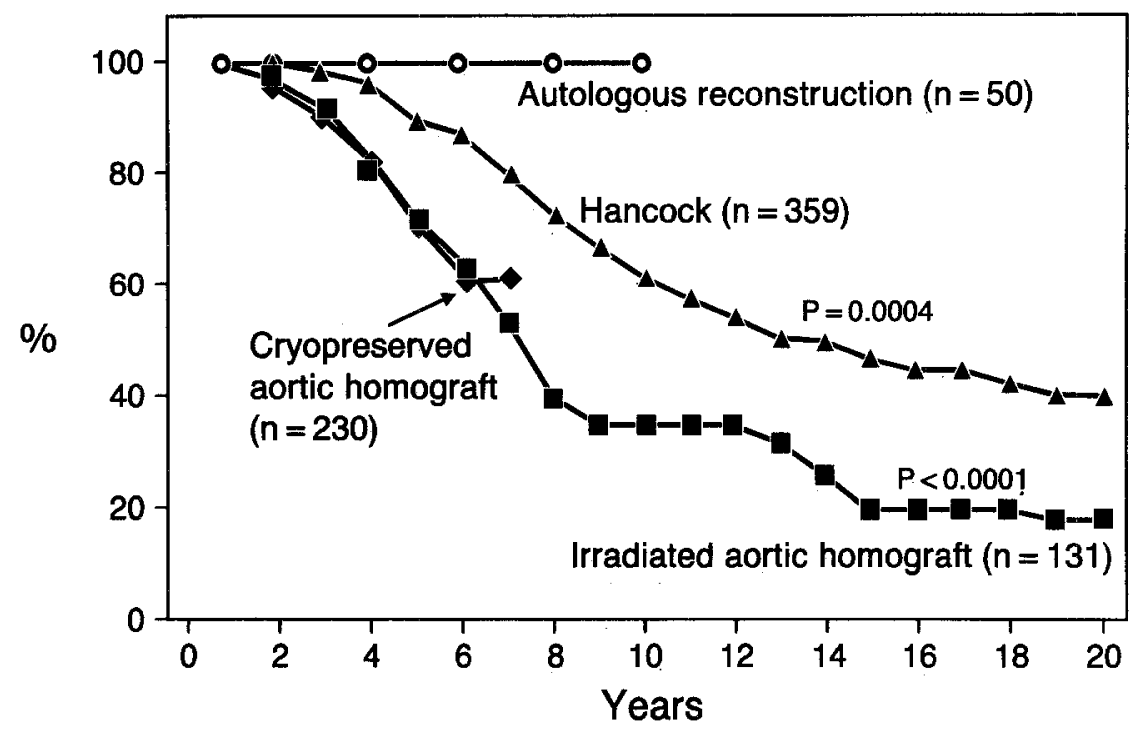

Fig. 4. Freedom from reoperation because of conduit failure for autologous tissue reconstruction, irradiated aortic homograft, cryopreserved aortic homograft, and Hancock conduits.

and correction of the tricuspid insufficiency with an annuloplasty. These three patients had no characteristics that, in retrospect, would have predicted the eventual need for a valve. However, they were older than the median age of patients receiving a nonvalved reconstruction, and all had two or more cardiac operations before the reconstruction. The large porcine valves that could be implanted in this series have remained failure-free to date, and evaluation of a larger $(n=359)$ and earlier series of porcine-valved Dacron PV-PA conduits has shown that survival free of reoperation is best for the largest sizes (unpublished data). Accordingly, in our more recent experience, we have been more liberal in our use of porcine bioprostheses in the autologous tissue reconstructions.

We have also had an extensive experience with cryopreserved aortic and pulmonary homografts, which were initially used in an effort to reduce the prevalence of late conduit failure. ${ }^{8}$ The follow-up of our series of cryopreserved aortic $(n=230)$ and pulmonary $(n=118)$ homografts extends to 8.8 years with a mean of 2.7 years for aortic homografts and 3.2 years for pulmonary homografts. ${ }^{8}$ The homograft series included both primary implantations and replacements of previous PV-PA conduits. The median age of the patients was less than that of patients in the reconstruction series ( 9 years for aortic homograft recipients and 12 years for pulmo- nary homograft recipients versus 16 years for patients in the autologous tissue reconstruction series), and none of the patients in the reconstruction series were 4 years old or less. Nevertheless, freedom from reoperation for cryopreserved aortic homograft failure was only $70 \%$ at 5 years, which is similar to the $72 \%$ freedom from reoperation for our earlier series of irradiated homografts $(n=131$, unpublished data) (Fig. 4). The cryopreserved pulmonary homografts fared better when graft failure was defined as conduit stenosis and insufficiency only, but when anastomotic false aneurysm was included in the definition, the 5-year freedom from reoperation for conduit failure was not significantly different from that of the cryopreserved aortic homografts.

The autologous tissue reconstruction has several potential advantages. First, by retaining the posterior and lateral portions of the explanted conduit fibrous bed, it maintains a surface of autologous tissue that does not form a progressive obstructive peel. In our experience, glutaraldehyde-preserved bovine pericardium used for the roof of the repair and for other reconstructive procedures on the pulmonary artery also does not form a progressive obstructive peel. Another advantage is that the diameter of the PV-PA conduit can be made as large as desired; it was of normal adult size or larger in all of the patients in this series. This technique also allows a large size of bioprosthesis to be in- 
serted that decreases the PV-PA gradient and associated turbulence and valve trauma to minimal levels, potentially delaying the development of valve deterioration and calcification and subsequent need for valve replacement. The distal portion of the pericardial patch may be tailored to allow easy enlargement of the proximal right and left pulmonary arteries, and in the majority of cases the construction can be done without the need for crossclamping the aorta.

Perhaps the most important criterion for evaluating the late function of an extracardiac conduit is to consider its survivorship free of the need for reoperation for conduit failure. Fig. 4 compares the survivorship free of reoperation because of conduit failure of the autologous tissue reconstruction with our previous results with the Hancock conduit ( $p=$ $0.0004)$, the irradiated homograft ( $p<0.0001)$, and the cryopreserved aortic homograft. The autologous tissue reconstruction compares favorably with the other types of conduits. Further extensive long-term evaluation of this technique seems warranted.

We gratefully acknowledge the secretarial support of Merrilee Rogotzke.

\section{REFERENCES}

1. Danielson GK, Downing TP, Schaff HV, Puga FJ, DiDonato RM, Ritter DG. Replacement of obstructed extracardiac conduits with autogenous tissue reconstructions. J Thorac CardiovasC Surg 1987;93:555-9.

2. Wallace RB, Rastelli GC, Ongley PA, Titus JL, McGoon DC. Complete repair of truncus arteriosus defects. J Thorac Cardiovasc Surg 1969;57:95-107.

3. Malm JR, Bowman FO Jr, Harris PD, Kowalik AT. An evaluation of aortic valve homografts sterilized by electron beam energy. J Thorac Cardiovasc Surg 1967;54:471-7.

4. Agarwal KC, Edwards WD, Feldt RH, Danielson GK, Puga FJ, McGoon DC. Clinicopathological correlates of obstructed right-sided porcine-valved extracardiac conduits. J THORAC CARDIOVASC SURG 1981;81:591601.

5. Agarwal KC, Edwards WD, Feldt RH, Danielson GK, Puga FJ, McGoon DC. Pathogenesis of nonobstructive fibrous peels in right-sided porcine-valved extracardiac conduits. J Thorac Cardiovasc Surg 1982;83:584-9.

6. Downing TP, Danielson GK, Schaff HV, Puga FJ, Edwards WD, Driscoll DJ. Replacement of obstructed right ventricular-pulmonary arterial valved conduits with nonvalved conduits in children. Circulation 1985; 72(Suppl):II84-7.

7. Murphy JG, Gersh BJ, Mair DD, et al. Long-term outcome in patients undergoing surgical repair of tetralogy of Fallot. N Engl J Med 1993;329:593-5.

8. Bando K, Danielson GK, Schaff HV, Mair DD, Julsrud PR, Puga FJ. Outcome of pulmonary and aortic homografts for right ventricular outflow tract reconstruction. J Thorac Cardiovasc Surg 1995;109:509-18.

\section{Discussion}

Dr. Edward L. Bove (Ann Arbor, Mich.). The procedure that we have just heard presented by Dr. Cerfolio from the Mayo Clinic group was first reported by them in 1987 and offers a simplified technique for the replacement of the obstructed PV-PA conduit by using the fibrous tissue bed, or conduit peel, of the explanted conduit to serve as the posterior wall of the pathway. The remainder of the pathway is fashioned by constructing a roof of prosthetic material or, as currently preferred by the authors, xenograft pericardium. The major advantage of the approach is to minimize operative dissection, particularly over the coronary arteries, which reduces the potential for injury and simplifies the procedure.

It is clear that the ideal conduit, one that will not result in obstruction and will provide a competent valve, is not available. Dacron conduits with heterograft tissue valves will all become obstructed in time as a result of fibrous tissue peel formation and leaflet calcification. The resurgence of allografts, either cryopreserved or fresh, has not proved to be the panacea that many had hoped. The obstructive problems of the latter, however, appear more common with the aortic than the pulmonary allografts, and data are now emerging to show that the durability of larger-size pulmonary allografts is quite excellent, particularly when Dacron extensions or hoods are avoided.

Thus it seems that reoperation because of conduit problems with use of the technique described by the Mayo Clinic group will be predicated on the status of the valve: reoperation will be required because of either obstruction in those patients with tissue valves or insufficiency in those without valves in whom signs and symptoms of right ventricular volume overload may eventually develop. Reoperation for late pulmonary valve insertion, however, should be uncommonly required, as the long-term follow-up of those patients with repaired tetralogy of Fallot with transannular right ventricular outflow tract patches has demonstrated. Therefore, as the Mayo Clinic group has already shown, it is important to carefully select those patients who will require a valve at the time of conduit replacement to ensure an optimal hemodynamic outcome for the longest possible duration. Patients with pulmonary artery hypertension because of unrelieved pulmonary artery stenoses, hypoplastic branch pulmonary arteries, and pulmonary vascular disease and those with left ventricular dysfunction are at the greatest risk of requiring valve insertion. Those with significant right ventricular dysfunction or unrepaired tricuspid insufficiency may also likely tolerate additional volume overload poorly.

When a valve is required, a tissue valve inserted in the conduit as described by the authors will provide excellent function and durability and will be superior to other Dacron conduits by avoiding recurrence of fibrous tissue 
peel formation. Insertion of a cryopreserved pulmonary allograft, however, will serve the same purpose, although the prevalence of regurgitation will be higher. If a valve is likely to be needed only during the early postoperative period to convey at least a transient hemodynamic benefit, the allograft may be the better option because the development of late valve regurgitation may not necessitate reoperation, whereas late tissue valve obstruction as a result of leaffet calcification will. Some groups have opted for insertion of a monocusp valve in these situations. Although the authors describe successful use of two mechanical valves in their patients, long-term results even with anticoagulation have not been ideal in this group.

I have three questions for Dr. Cerfolio. What are the limitations of this technique and when would the authors select an allograft conduit instead? Second, what are the indications for use of a mechanical valve? Finally, do the authors have any late data on right ventricular function or aneurysm formation in these patients?

Dr. Cerfolio. Dr. Bove's first questions concern the limitations of the technique and when would we choose to use an allograft. The technique is currently limited to replacement of a previous conduit. Tightly woven Dacron fabric produces the best fibrous bed for the reconstruction, but we have done this operation after explantation of other types of conduits including polytetrafluoroethylene tubes and homografts.

In a recent study published by Bando and colleagues ( $\mathrm{J}$ Thorac CARdiovasc Surg 1995;109:509-18), we looked at late results of cryopreserved pulmonary and aortic homografts. Although we did find that pulmonary homografts in the right ventricular position fared better than aortic homografts, the definition of conduit failure that was used did not include aneurysm formation at the anastomoses, as it did in this paper. When one includes that complication in the definition, freedom from conduit failure of the pulmonary homograft was not statistically different from that of the aortic homograft. In view of the aneurysm problem and the increasing prevalence of late valve insufficiency in pulmonary homografts, especially when pulmonary hypertension is present, we tend to use autologous reconstructions for conduit reoperations, except perhaps for patients younger than age 4 years.

The next question concerned the indication for use of a mechanical valve. Mechanical valves are used infrequently. Both patients with mechanical valves in this series had pulmonary hypertension and previous bioprosthetic valve failures. Both receive anticoagulation and the valves in both are functioning well 11 and 8 years after operation, respectively.

With regard to the last question, there were no false aneurysms in this series of autologous tissue reconstructions. Symptoms of the right side of the heart, an enlarging right ventricle, and concern about decreasing right ventricular ejection fraction were factors that influenced the decision for placement of a pulmonary valve in three patients who initially had received a nonvalved reconstruction.

Dr. Guillermo O. Kreutzer (Buenos Aires, Argentina). If the authors' philosophy is to use autologous tissue, my question is this: why not use it from the beginning when no pericardial adhesions are present?
Since 1983 we have been using an unpreserved autologous pericardial bicuspid valve conduit constructed as large as possible with a minimum diameter according to the surface area requirements. We reviewed the intermediate and long-term follow-up of all 51 patients with an age range from 1 year to 10.4 years (median 5 years). The original conduit diameter implanted ranged from 12 to 20 $\mathrm{mm}$ (median $16 \mathrm{~mm}$ ).

At follow-up 1 month after operation with twodimensional Doppler echocardiography, there was no or trivial conduit valve regurgitation. At the most recent follow-up, the median gradient was $21 \mathrm{~mm} \mathrm{Hg}$. The diameter increased 1 to $7 \mathrm{~mm}$ in 27 patients, did not change in 20 , and only in 4 was there a reduction of 1 to $2 \mathrm{~mm}$. Six reoperations were done related to gradients. Four of these were at the distal anastomosis line and in conduits implanted before 1986. At that time we had started to complete the distal anastomosis over a Hegar bougie and to use polydioxanone sutures in four quadrants.

The actuarial freedom from reoperation was $90 \%$ at 5 years and $100 \%$ for conduits measuring more than $16 \mathrm{~mm}$ at the time of implantation. After the technical modification in 1986, the actuarial survival and freedom from reoperation was $96.6 \%$ at 7 years. Long-term follow-up compared favorably with that for the cryopreserved homograft with a lower prevalence of reoperations. In our opinion this conduit is the only one that has the tendency to increase its diameter. Furthermore, it is less expensive and, in addition, represents a valid option for the Ross operation.

Dr. Cerfolio. We do not have any experience with an autologous pericardial bicuspid conduit. However, Dr. Kreutzer touched on a couple of points that I think our technique also includes. First of all, we do have one patient who had a previous pulmonary homograft who underwent reoperation because of insufficiency and obstruction, and in that patient we tried to do an endarterectomy in the calcified part of the homograft. However, the floor of the tissue bed was not well formed, so we used a pericardial tube, valved with a bioprosthesis, similar to what Dr. Kreutzer discussed. It is of interest that a pericardial tube was the first conduit used for complete repair of a congenital heart defect. This was done by Dr. John Kirklin at the Mayo Clinic in 1964. That conduit has not necessitated reoperation in a follow-up of 29 years.

Second, the point about the diameter of the conduit is important. One is able to tailor the diameter of our conduit by sizing the patch of pericardium over a dilator. One can therefore make the diameter any size that is desired.

Dr. Charles A. Yankah (Berlin, Germany). We have followed up 163 of 202 patients with aortic and pulmonary homograft valves in the right ventricular outflow tract (mostly pulmonary homografts) and examined the problems involved. We used the standard surgical method with a hood, usually polytetrafluoroethylene, at the proximal anastomotic site. We treated our patients with antiinflammatory drugs (aspirin), and I think this is an important issue, because we usually observe infiltrations of inflammatory cells in the viable valves. We studied a group of 40 children younger than age 2 years 
to identify risk factors for early degeneration in this group of patients. It was interesting to see that the pulmonary homograft did better than the aortic homograft in this younger age group.

The pulmonary homograft showed $100 \%$ freedom from early calcification as compared with $19 \%$ for the aortic homograft at 20 months. Freedom from reoperation for the aortic and pulmonary homografts was $69 \%$ and $100 \%$ at 48 months, respectively.

In summary, we are convinced that the pulmonary homograft will do better in the right ventricular outflow tract in children in conjunction with the use of antiinflammatory drugs.

Dr. Cerfolio. In the previously mentioned review by Bando and colleagues, there was an accelerated failure of the homografts in both positions, especially the aortic, in children younger than age 4 years. In some of the patients, homograft calcification was not present, but the tissues were contracted and edematous, and thrombus was seen in the retracted cusps. Some of these findings occurred within 2 years of implantation, and they had the appearance of an immunologic response. It will be interesting to see whether aspirin will be effective in preventing such changes.

Mr. Jaroslav F. Stark (London, England). We have used this excellent technique in some special circumstances. If one uses homograft for the first operation, one does not get the fibrous bed as the authors have shown for heterograft. Thus I would like to ask the authors, in view of their excellent experience, whether they modified their approach to insertion of the first homograft by using either homografts or heterografts in the Dacron tube and abandoning aortic and pulmonary homografts?

Dr. Cerfolio. Mr. Stark has raised an interesting question. Should a Dacron tube, either valved or nonvalved, be used as the first conduit so that a good fibrous bed will be formed for an autologous tissue reconstruction when conduit replacement is required? It is true that our enthusiasm for cryopreserved homografts is waning. Perhaps a preliminary Dacron conduit subsequently replaced by an autologous tissue reconstruction will prove to have the greatest utility and longevity. Which conduit and in what order are questions that probably will be resolved only by further experience and follow-up.

\section{Bound volumes available to subscribers}

Bound volumes of THE JOURNAL OF THORACIC AND CARDIOVASCUlaR SURgery are available to subscribers (only) for the 1995 issues from the Publisher, at a cost of $\$ 91.00$ for domestic, $\$ 118.77$ for Canadian, and $\$ 111.00$ for international subscribers for Vol. 109 (January-June) and Vol. 110 (July-December). Shipping charges are included. Each bound volume contains a subject and author index and all advertising is removed. Copies are shipped within 60 days after publication of the last issue of the volume. The binding is durable buckram with the Journal name, volume number, and year stamped in gold on the spine. Payment must accompany all orders. Contact Mosby-Year Book, Inc., Subscription Services, 11830 Westline Industrial Drive, St. Louis, Missouri 63146-3318, USA; phone 1 (800) 453-4351 or (314) 453-4351.

Subscriptions must be in force to qualify. Bound volumes are not available in place of a regular JouRNal subscription. 